\title{
Impact of Farming Models on the Reproductive Performance and Egg Quality of Vietnamese Local Chicken Breeds: Ho and Dong Tao
}

\author{
Nguyen Van Duy ${ }^{1,2}$, Hoang Ngoc Mai ${ }^{1}$, Nguyen Dinh Tien ${ }^{1}$, \\ Nguyen Thi Phuong ${ }^{1} \&$ Vu Dinh Ton ${ }^{1}$ \\ ${ }^{1}$ Faculty of Animal Science, Vietnam National University of Agriculture, Hanoi, 131000 \\ Vietnam \\ ${ }^{2}$ Faculty of Veterinary Medicine, University of Liege, Liege 4000, Belgium
}

\begin{abstract}
The study was conducted from October 2016 to December 2017 at the Experimental Farm, Faculty of Animal Science, Vietnam National University of Agriculture, with the aim to evaluate the interaction between farming model types and reproductive performance of Ho and Dong Tao chickens. The two farming model types used in this research were (1) the traditional type - backyard and (2) the ameliorate type - battery cage. Data were collected from 61 Ho hens and 61 Dong Tao hens continuously during 52 laying weeks. The total number of eggs laid by hens raised in battery cages averaged 88.47 eggs (for Ho hens) and 94.91 eggs (for Dong Tao hens), 35-38\% higher than the number of eggs laid by hens raised in a traditional model. The FCR index per 10 eggs laid in battery cages was significantly lower than that in the back-yard model $(\mathrm{P}<0.001)$. In both the Ho and Dong Tao breeds, the rate between the number of embryonated eggs by number of incubated eggs recorded in the ameliorate model was higher than that recorded in the traditional model ( $\mathrm{P}<0.01$ for Ho chickens, $\mathrm{P}<0.001$ for Dong Tao). The weight of eggs produced by hens raised in battery cages was higher than eggs laid by free-range hens for both Ho and Dong Tao chickens $(\mathrm{P}<0.01)$. As such, the reproductive performances and egg quality of both Ho and Dong Tao breeds were apparently improved when chickens were raised in battery cages.
\end{abstract}

\section{Keywords}

Received: January 2, 2019

Battery cage models, farming, indigenous chicken, systems traditional, Dong Tao chicken, Ho chicken

\section{Correspondence to}

vdton@vnua.edu.vn

\section{ORCID}

Vu Dinh Ton https://orcid.org/0000-0002-20418901

\section{Introduction}

Chicken farming in Vietnam has been actively transformed in recent decades, leading to a significant improvement in meat and egg 
performance. Many chicken breeds with high potential have been implemented in the country. Chicken farming systems have been also mechanized and well-constructed with feeding and drinking systems, light control, and sewage treatment systems. The influence of farming models on egg productivity and quality has previously been published. In detail, caged hens were shown to produce higher numbers of eggs in comparison with eggs laid by cage-free hens; however, a high population density of chickens raised in cages conclusively caused symptoms of stress in chickens, possibly leading to reductions of productivity and disease resistance (Özbey \& Esen, 2007). Chicken genotypes and cage construction styles were reported to affect egg weight, yolk weight, and shell weight $(\mathrm{P}<0.01)$ (Tůmová et al., 2011).

The genetic sources of Vietnamese local chickens are diverse (Berthouly et al., 2009). Traditionally, Vietnamese local chicken breeds were named after their original village or their typical appearance. In Vietnam, there are about 21 local chicken breeds (MARD, 2016). The backyard farming model has been implemented by up to $92 \%$ of all chicken farming households (FAO, 2008), covering 84-85\% of farming households in North Eastern and North Western Vietnam (Lan Phuong et al., 2015).

Ho and Dong Tao chickens belong to the most important local chicken breeds in Vietnam because of their first-class meat quality, historically regarded as traditional delicacies for the king (FAO, 2008). Ho chicken originates from Ho village, Thuan Thanh district, Bac Ninh province in Northern Vietnam, and features typical morphological characteristics, including a massive body size and diversified feather colors (Nguyen Van Duy et al., 2015). Meanwhile, Dong Tao chicken originates from Dong Tao village, Khoai Chau district, Hung Yen province in Northern Vietnam, and is characterized by enlarged feet, massive body size, and large feather-color diversity (Nguyen Van Duy et al., 2017). In general, Ho and Dong Tao chicken farming are practised mostly at a small farming scale and not under the management of local authorities (Ngo Thi Kim Cuc, 2010; Pham et al., 2013). The population of Dong Tao chickens consists of more than 1,000 Dong Tao chicken households, totaling nearly 10,000 individuals. Of these, only about 20 farms have a flock size exceeding 50 hens per household (Dao Thi Hiep, 2013). The population of Ho chickens is very small, with only 1,404 individuals distributed among 88 households (Bui Huu Doan \& Nguyen Van Luu, 2006).

The fact that Ho and Dong Tao chickens have low reproductive performances while being raised in a traditional-style farming model generates an interest in alternative farming models to enhance egg productivity. For this reason, this project aims to compare the impact of a traditional farming model and a battery-cage system on the reproductive performance and egg quality of Ho and Dong Tao chickens.

\section{Materials and Methods}

This research was conducted from October 2016 to December 2017 at the experimental farm of the Faculty of Animal Science, Vietnam National University of Agriculture in Hanoi (Vietnam). Hanoi is located at the latitude of $21^{\circ} 0278^{\prime}$ North and at the longitude of $105^{\circ}$ $8432^{\prime}$ East. The weather is sub-tropical, and the total sunshine time is about 1075.2 hours during the year. Average monthly temperatures range from $25.1^{\circ} \mathrm{C}$ in June to $18.1^{\circ} \mathrm{C}$ in December. Average annual humidity is about $76.6 \%$, with the highest (84\%) in March and the lowest (70\%) in December (GSO, 2018). The project contained two parallel supervisions of Ho and Dong Tao chickens. In this research, qualitative and quantitative criteria showing reproductivity and egg quality were recorded continuously during the 52 weeks of the laying period. The quality of the eggs was evaluated in terms of weight, length, width, and the egg shape index.

\section{Egg productivity and quality}

The criteria of egg productivity were investigated on 122 Ho and Dong Tao hens (61 hens/breed: 25 hens in a traditional backyard system and 36 hens in a battery cage model). The hens were settled in two different farming model types 15-20 days before laying their first egg. The traditional farming model was constructed with a simple chicken house, a soil-made playing 
yard for chickens at a density of 01 chicken $/ \mathrm{m}^{2}$, an appropriate design for natural light, was equipped with rain covers and rice-husks spread on the floor, and was surrounded by shade trees. For experimental purposes, in each of flocks, a cock was maintained to create a "family" at the rate of 5 hens/1 cock. Alternatively, the second experimental farming model included a multicell battery cage (cell dimensions: length $\mathrm{x}$ width $\mathrm{x}$ height $=40 \times 65 \times 38 \mathrm{~cm})$. The caging blocks were kept at a distance of $60 \mathrm{~cm}$ above the ground. Each cell had a separate door tagged with a number corresponding to a wing code. The hens were illuminated for 16 hours per day and the hens were inseminated artificially every two days using $0.05 \mathrm{~mL}$ semen doses.

In both experimental farming models, all the hens were provided enough drinking water and fed comfortably with the same diet (Table 1). Reproductive performance was tested for 52 weeks after the first-egg laying age. Qualified eggs were collected every day and stored at room temperature. Among those, eggs collected on Monday and Tuesday were qualified and quantified every Wednesday. Good eggs collected on the other days were hatched. Abnormal eggs (eg. cracked, ruptured, unshelled, etc.) were eliminated.

Eggs were weighed individually using an electronic balance with a $\pm 0.01 \mathrm{~g}$ accuracy.
Average weight was calculated based on the weight of every egg during the 52 laying weeks. Each egg's length and width were measured in the same way, using electronic sliders with a $\pm 0.01 \mathrm{~mm}$ accuracy. The shape index was calculated to be equal to the ratio of the length and width. All qualified eggs were incubated using an automatic multi-period electric incubator with a maximum capacity of 500 eggs. The embryonic status was checked after 7 days of incubation by screening under direct white light. The number of embryonated eggs, newborn chicks, and deformed new-born chicks were recorded. The ratio of embryonated eggs/total incubated eggs and new-born chicks/total embryonated eggs were calculated in detail.

\section{Statistical analysis}

The data were analyzed using with SAS 9.1. the MEANS procedure was used to calculate means and standard errors (SE). The ANOVA procedure was used to test the differences between means of the two farming models with the significance level set at $\mathrm{P}<0.05$.

\section{Results}

\section{Reproductive traits and egg production}

The data on laying percentage of Ho and Dong Tao chickens is shown in Figure 1. Generally, the laying rate of Ho and Dong Tao

Table 1. Ingredients and nutritive composition of the diet for the laying hens

\begin{tabular}{|c|c|}
\hline Ingredients & Proportion (\%) \\
\hline Corn & 34.00 \\
\hline Concentrated feed ${ }^{1}$ & 16.50 \\
\hline Rice bran & 16.00 \\
\hline Paddy & 33.00 \\
\hline Premix Mineral -vitamins ${ }^{2}$ & 0.50 \\
\hline \multicolumn{2}{|c|}{ Nutritive composition of the $\operatorname{diet}\left(\mathrm{g} \mathrm{kg}^{-1}\right)$} \\
\hline Crude protein $(\mathrm{CP})$ & 142.5 \\
\hline Fat content & 53.46 \\
\hline Calcium & 6.50 \\
\hline Phosphorus & 5.90 \\
\hline Fiber & 42.21 \\
\hline Metabolizable energy (kcal kg-1) & 3030.12 \\
\hline
\end{tabular}

Note: ${ }^{1}$ Protein-rich feed, crude protein 45\%; ${ }^{2}$ vitamin A: $3000000 \mathrm{Ul} \mathrm{kg}^{-1}$, vitamin D3: $30000 \mathrm{Ul} \mathrm{kg}^{-1}$, vitamin E: $100 \mathrm{mg} \mathrm{kg}^{-1}$ 
chickens is shown in Figure 1. Generally, the laying rate of Ho and Dong Tao chickens was low. The laying rate of Ho hens was lower than that of Dong Tao hens. The laying rate of these two breeds varied by about $20 \%$.

The influence of the farming model type on the reproductive performance of Ho and Dong Tao chickens is analyzed in Tables 2 and 3. In both experimental breeds, almost all the remarkable indicators of egg productivity showed considerable relationships with the farming model types.

The production yield during the 52 laying weeks of Ho hens raised in battery cages was 88.47 eggs on average, which was $35 \%$ higher than the number of eggs laid by Ho hens freely released in a traditional farming model $(\mathrm{P}<0.05$, Table 2). Meanwhile, egg productivity of Dong Tao hens raised in battery cages during the 52 laying weeks was 94.91 eggs on average, which was $38 \%$ higher than the number of eggs laid by hens raised in a conventional model $(\mathrm{P}<0.05$, Table 3). The amount of feed consumed by the hens per day, the feed consumption for 52 weeks, the feed conversion ratio to produce 10 eggs, and the FCR were significantly correlated with the flock type in both Ho and Dong Tao breeds. Data analyses in Tables 2 and 3 revealed an apparent disparity in feed consumption for hens raised in battery cages compared to hens raised in a traditional style, with the domination belonging to the earlier group.

The egg hatchability criteria also showed a tight correlation with the farming model types. Concretely, the number of qualified eggs for incubation, number of embryonated eggs, embryonated eggs/incubated eggs ratio, and hatched eggs/incubated eggs ratio were significantly correlated with the farming model types in both Ho and Dong Tao breeds $(\mathrm{P}<0.01$; $\mathrm{P}<0.001$ ) (Tables 4 and 5). The embryonated eggs/incubated eggs ratio of eggs laid by hens in a ameliorate farming model type was higher than those of the hens raised in traditional type by about $13 \%$ for Ho chickens and $18 \%$ for Dong Tao.

Similarly, the ratio of hatched eggs/incubated eggs was very different between the two farming model types with the dominance belonging to the hens raised in battery cages $(\mathrm{P}<$ 0.001). On the contrary, there were no differences between the two farming model types in the hatched eggs/fertile eggs ratio and chick malformation ratio for the two chicken breeds.

$(\% /$ hen/week) 60

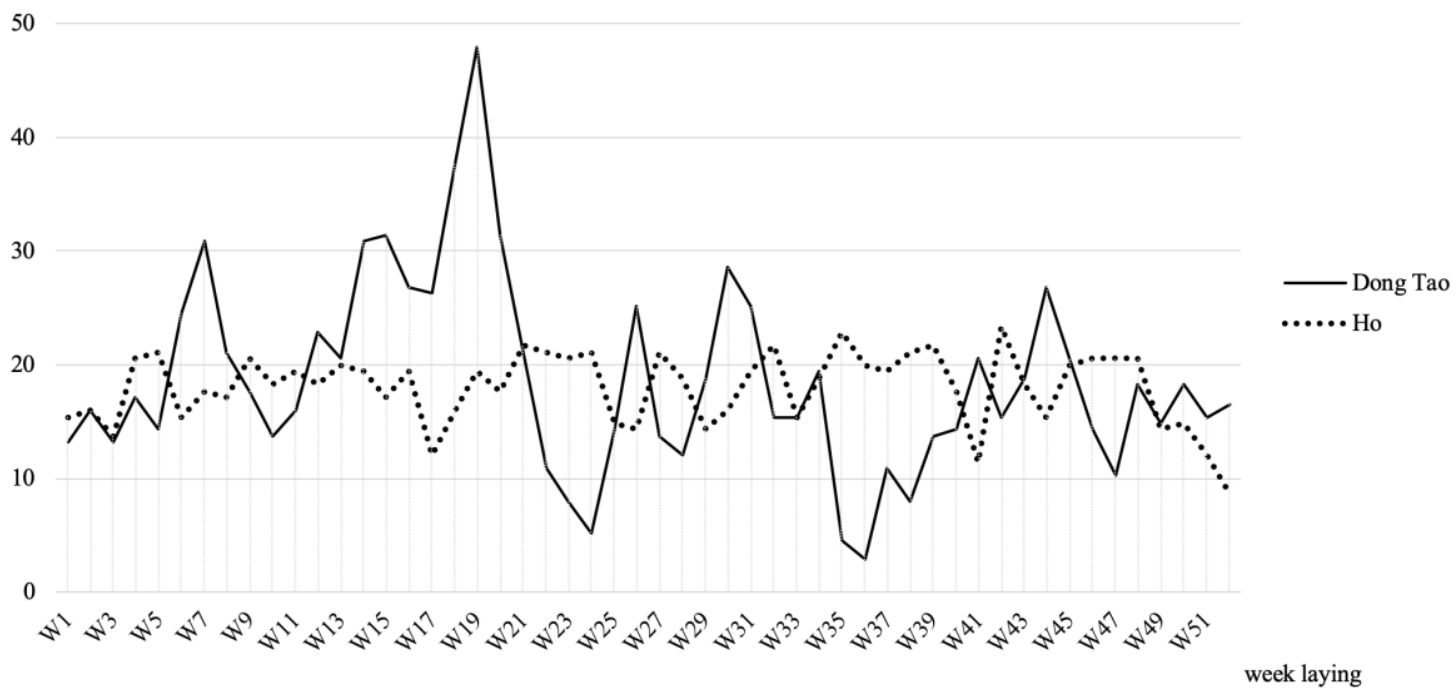

Figure 1. Laying percentage of Ho and Dong Tao chickens in the battery cage model by weeks 
Table 2. Laying performance and feed consumption of Ho hens by farming model types

\begin{tabular}{|c|c|c|c|c|c|}
\hline \multirow{2}{*}{ Criteria } & \multicolumn{2}{|c|}{ Battery cage model } & \multicolumn{2}{|c|}{ Traditional model } & \multirow{2}{*}{$\mathbf{P}$} \\
\hline & $\mathbf{n}_{1}$ & Means \pm SE & $\mathbf{n}_{2}$ & Means \pm SE & \\
\hline $\begin{array}{c}\text { Total number of eggs in } 52 \text { weeks of } \\
\text { laying (eggs) }\end{array}$ & 36 & $88.47 \pm 3.87$ & 5 & $65.52 \pm 8.23$ & * \\
\hline Feed consumption per hen per day $(\mathrm{g})$ & 36 & $105.97 \pm 0.71$ & 5 & $97.32 \pm 1.84$ & *** \\
\hline $\begin{array}{l}\text { Feed consumption per hen in } 52 \text { weeks } \\
\text { of laying }(\mathrm{kg})\end{array}$ & 36 & $38.57 \pm 0.25$ & 5 & $35.42 \pm 0.67$ & $* * *$ \\
\hline $\begin{array}{l}\text { Feed conversion ratio (FCR/10 eggs) } \\
\qquad(\mathrm{kg})\end{array}$ & 36 & $4.36 \pm 0.03$ & 5 & $5.40 \pm 0.10$ & *** \\
\hline
\end{tabular}

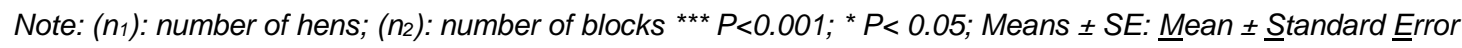

Table 3. Laying performance and feed consumption of Dong Tao hens by farming model types

\begin{tabular}{|c|c|c|c|c|c|}
\hline \multirow{2}{*}{ Criteria } & \multicolumn{2}{|c|}{ Battery cage model } & \multicolumn{2}{|c|}{ Traditional model } & \multirow{2}{*}{$\mathbf{P}$} \\
\hline & $\mathbf{n}_{1}$ & Means \pm SE & $\mathbf{n}_{2}$ & Means \pm SE & \\
\hline $\begin{array}{c}\text { Total number of eggs in } 52 \text { weeks of } \\
\text { laying (eggs) }\end{array}$ & 36 & $94.91 \pm 4.40$ & 5 & $68.92 \pm 8.61$ & * \\
\hline Feed consumption per hen per day $(\mathrm{g})$ & 36 & $105.79 \pm 0.60$ & 5 & $96.24 \pm 2.01$ & *** \\
\hline $\begin{array}{c}\text { Feed consumption per hen in } 52 \text { weeks } \\
\text { of laying }(\mathrm{kg})\end{array}$ & 36 & $38.51 \pm 0.22$ & 5 & $34.80 \pm 0.76$ & *** \\
\hline $\begin{array}{l}\text { Feed conversion ratio (FCR/10 eggs) } \\
\qquad(\mathrm{kg})\end{array}$ & 36 & $4.06 \pm 0.02$ & 5 & $4.57 \pm 0.09$ & *** \\
\hline
\end{tabular}

Note: $\left(n_{1}\right)$ : number of hens; $\left(n_{2}\right)$ : number of blocks; ${ }^{* *} P<0.001 ;{ }^{*} P<0.05 ;$ Means $\pm S E:$ Mean \pm Standard Error

Table 4. Fertilizing ability of Ho chickens by farming model types

\begin{tabular}{|c|c|c|c|c|}
\hline \multirow{2}{*}{ Criteria } & \multicolumn{2}{|c|}{ Battery cage model } & \multicolumn{2}{|c|}{ Traditional model } \\
\hline & $\mathbf{n}$ & Means \pm SE & $\mathbf{n}$ & Means $\pm \mathrm{SE}$ \\
\hline Incubated eggs (eggs) & 46 & $27.15 \pm 2.10$ & 61 & $12.42 \pm 0.28$ \\
\hline Embryonated eggs (eggs) & 46 & $24.04 \pm 1.89$ & 61 & $8.93 \pm 0.25$ \\
\hline $\begin{array}{l}\text { Embryonated eggs/incubated eggs ratio } \\
\qquad(\%)\end{array}$ & 46 & $88.27 \pm 0.82$ & 61 & $75.52 \pm 1.82$ \\
\hline Hatched eggs/incubated eggs ratio (\%) & 46 & $75.09 \pm 1.38$ & 61 & $61.78 \pm 1.41$ \\
\hline $\begin{array}{c}\text { Hatched eggs/embryonated eggs ratio } \\
(\%)\end{array}$ & 46 & $85.19 \pm 1.47$ & 61 & $85.95 \pm 1.20$ \\
\hline Chick malformation ratio (\%) & 46 & $1.74 \pm 3.19$ & 61 & $1.27 \pm 0.58$ \\
\hline
\end{tabular}

Note: (n): number of incubation batches; ${ }^{* *} P<0.001 ;{ }^{* *} P<0.01 ; N S: P>0.05 ;$ Means \pm SE: Mean \pm Standard Error 
Impact of Farming Models on the Reproductive Performance and Egg Quality of Vietnamese Local Chicken Breeds

Table 5. Fertilizing ability of Dong Tao chickens by farming model types

\begin{tabular}{ccccc}
\hline & \multicolumn{2}{c}{ Battery cage model } & \multicolumn{2}{c}{ Traditional model } \\
\cline { 2 - 5 } Criteria & $\mathbf{n}$ & Means \pm SE & $\mathbf{n}$ & Means \pm SE \\
\hline $\begin{array}{c}\text { Incubated eggs (eggs) } \\
\text { Embryonated eggs (eggs) }\end{array}$ & 47 & $36.36 \pm 1.43$ & 35 & $14.08 \pm 1.41$ \\
$\begin{array}{c}\text { Embryonated eggs/incubated } \\
\text { eggs ratio (\%) }\end{array}$ & 47 & $32.10 \pm 1.26$ & 35 & $9.85 \pm 0.99$ \\
$\begin{array}{c}\text { Hatched eggs/incubated eggs } \\
\text { ratio (\%) }\end{array}$ & 47 & $88.70 \pm 0.90$ & 35 & $70.55 \pm 1.42$ \\
$\begin{array}{c}\text { Hatched eggs/embryonated eggs } \\
\text { ratio (\%) }\end{array}$ & 47 & $75.73 \pm 1.24$ & 35 & $58.87 \pm 2.52$ \\
Chick malformation ratio (\%) & 47 & $85.46 \pm 1.21$ & 35 & $83.52 \pm 3.32$ \\
\hline
\end{tabular}

Note: (n): number of incubation batches; ${ }^{* * *} P<0.001 ; N S: P>0.05 ;$ Means \pm SE: Mean \pm Standard Error

Table 6. Weight and external egg quality measurements of Ho hens by farming model type

\begin{tabular}{cccc}
\hline Criteria & $\begin{array}{c}\text { Battery cage model } \\
(\mathbf{n = 1 0 8 0})\end{array}$ & $\begin{array}{c}\text { Traditional model } \\
(\mathbf{n}=\mathbf{5 8 6})\end{array}$ & $\mathbf{P}$ \\
\cline { 2 - 3 } & Means \pm SE & Means \pm SE & $* \star$ \\
Weight $(\mathrm{g})$ & $51.43 \pm 0.17$ & $50.37 \pm 0.18$ & $\mathrm{NS}$ \\
Length $(\mathrm{mm})$ & $52.47 \pm 0.09$ & $52.95 \pm 0.10$ & $\mathrm{NS}$ \\
Width $(\mathrm{mm})$ & $41.63 \pm 0.05$ & $41.65 \pm 0.07$ & $\mathrm{NS}$ \\
Shape index & $1.26 \pm 0.35$ & $1.27 \pm 0.15$ & \\
\hline
\end{tabular}

Note: $(n)$ : number of specimens; ${ }^{* *} P<0.01 ; N S: P>0.05$; Means \pm SE: Mean \pm Standard Error

Table 7. Weight and external egg quality measurements of Dong Tao hens by farming model type

\begin{tabular}{|c|c|c|c|}
\hline \multirow[t]{2}{*}{ Criteria } & $\begin{array}{l}\text { Battery cage model } \\
\qquad(n=1723)\end{array}$ & $\begin{array}{l}\text { Traditional model } \\
\qquad(n=1106)\end{array}$ & \multirow[t]{2}{*}{ P-value } \\
\hline & Means \pm SE & Means \pm SE & \\
\hline Weight (g) & $51.69 \pm 0.19$ & $50.55 \pm 0.14$ & $* *$ \\
\hline Length (mm) & $53.81 \pm 0.11$ & $52.81 \pm 0.08$ & $* * *$ \\
\hline Width (mm) & $40.79 \pm 0.22$ & $41.39 \pm 0.06$ & $* * *$ \\
\hline Shape index & $1.32 \pm 0.38$ & $1.28 \pm 0.11$ & $* * *$ \\
\hline
\end{tabular}

Note: $(n)$ : number of specimens; ${ }^{* *} P<0.01 ;{ }^{* *} P<0.001 ;$ Means $\pm S E:$ Mean \pm Standard Error

\section{Weight and external egg quality}

The indicators of weight and external egg quality measurements are presented in Table 6 (for Ho breed) and Table 7 (for Dong Tao breed). For Ho chickens, the weight of eggs produced by hens raised in battery cages was slightly higher than the weight of eggs produced by hens raised in the conventional farming model $(51.43 \mathrm{~g}$ and $50.37 \mathrm{~g}$, respectively, $\mathrm{P}<0.01)$. Other criteria about egg size (length, width, and shape index) showed no significant correlations with the farming model types (P> 0.05). For Dong Tao 
chickens, the difference of egg weights produced by hens raised in the two models was statistically meaningful $(\mathrm{P}<0.01)$. The egg size criteria revealed a significant correlation with the farming model types $(\mathrm{P}<0.001)$. Overall, the size of eggs laid by Dong Tao hens raised in a traditional flock were slightly higher than the size of eggs laid by Dong Tao hens raised in cages (Table 7).

\section{Discussion}

\section{Reproductive traits and egg production}

Poultry reproductive performance is strongly regulated by genetic factors (Dottavio et al., 2001). In this study, the egg productivity of Ho and Dong Tao chickens raised in traditional and battery cage models were recorded as 65.5288.47 eggs/hen/laying year and 68.92-94.91 eggs/hens/laying year, respectively. Egg production depended on the farming model type. Compared to other studies, the laying performances of these two breeds were higher than that of fighting chickens (54.04 eggs/hen/year) and the Mia breed (55-60 eggs/hen/year) (MARD, 2016). However, the egg productivities of Ho and Dong Tao chickens were intensely lower than that of Ri chickens (123 eggs/hen/year) (FAO, 2008). The reproductive cycles of $\mathrm{Ho}$ and Dong Tao chickens usually last 2-3 weeks, with the frequency of one egg per 2-3 days. After the laying period, hens entered an incubation stage lasting about 3 weeks. Recently, small automatic incubators (500 eggs per plant) have been popularly used in farming households for egg incubation. This has contributed to an increase in egg production by decreasing the incubating period. In some cases, farmers use female turkeys for incubating. The purpose of these practices is to increase the hatching rates, and to also push the next reproductive cycle of the hens. However, the habit of hatching without eggs in Ho and Dong Tao hens is mostly unavoidable.

Our results show that egg productivity of hens raised in battery cages was significantly higher than those raised in a traditional farming model type. This observation is compatible with the results of a previous study, in which the authors mentioned that stress might be an influential factor on changing physiological behaviors of laying hens (Özbey \& Esen, 2007).

According to our data, feed consumption for hens raised in battery cages was relatively higher than those raised in a traditional production type. The narrow space possibly stimulated the eating demand of the chickens. Nonetheless, the egg reproductive performance of chickens raised in battery cages was significantly higher than that of chickens raised on the ground, resulting in a more effective feed conversion ratio per 10 eggs recorded.

The rates of embryonated eggs in the Ho and Dong Tao experimental populations in the traditional model were considerably lower than that of other local chicken breeds. In detail, this rate in Ho and Dong Tao chickens was $75.52 \%$ and $70.55 \%$, respectively, compared to this indicator in multi-toe chickens $(80.45 \%)$ ( Nguyen Hoang Thinh et al., 2017) and in H'mong chickens $(89.56 \%$ ) (Duong Thi Anh Dao \& Vu Thi Cuc, 2011). The massive bodies of Ho and Dong Tao chickens, which causes difficulties in mating, elucidates this low fertile. Besides, semen quality of Ho and Dong Tao cocks is not high (Do Thi Hue et al., 2017).

\section{Weight and external egg quality parameters}

This study showed that there was a significant difference in egg weight of both chicken breeds by farming model types. This result encounters a conflict with a previous report, which stated that eggs laid by chickens raised on the ground were heavier than those laid by chickens raised in battery cages (Özbey \& Esen, 2007). However, a significant correlation between farming models and egg weight was also recorded in another research paper which showed that the eggs from cages were heavier than those from the litter (Tůmová et al., 2011).

Egg weight is an indicator influenced by chicken body weight and genetic factors (Moula et al., 2009). In this study, the weight of eggs produced by Ho and Dong Tao chickens raised in two experimental farming model types were 50.37-51.43g and 50.55-51.69g, respectively. Meanwhile, the egg weight of H'mong chickens and multi-toe chickens were $38.10 \mathrm{~g}$ (Nguyen Thi Phuong et al., 2017) and 39.70g ( Nguyen Hoang 
Thinh et al., 2017) on average, respectively. It can be seen that the egg weight of Ho and Dong Tao chickens was considerably higher than those of other local breeds. In addition, the egg shape index of Ho and Dong Tao eggs were 1.26-1.27 and $1.28-1.32$, respectively. According to our results, the egg shape index of chickens raised in battery cages was higher than those raised in the traditional model. This conclusion was also reported in the literature (Özbey \& Esen, 2007) with the shape indices of eggs being $77.65 \%$ for eggs from cages and $75.39 \%$ for eggs from the ground.

\section{Conclusions}

The reproductive performance of $\mathrm{Ho}$ and Dong Tao chickens raised in battery cages showed considerable differences compared to chickens raised in a traditional farming model. The feed conversion ratio to produce 10 eggs for hens raised in the battery cages model was significantly lower than those raised in the conventional farming model. The weight of eggs produced by Ho and Dong Tao hens raised in battery cages were better compared to the traditional way.

Our recordings and analyses in this study result in an implication that egg hatchability of these two valuable local chicken breeds can be considerably improved when the ameliorate farming model type was applied. However, the concern of animal welfare should remain when considering farming model types in real scale.

\section{Acknowledgements}

We would like to express our highest appreciation for the Académie de Recherche et d'Enseignement supérieur Commission de la Coopération au Développement (ARES - CCD) (Belgium) for its financial support to complete this research project.

\section{References}

Berthouly C., Leroy G., Van T. N., Thanh H. H., Bed'hom B., Nguyen B. T., Vu C. C., Monicat F., Tixierboichard M., Verrier E., Maillar J. C. \& Rognon X. (2009). Genetic analysis of local Vietnamese chickens provides evidence of gene flow from wild to domestic populations. BioMed Central Genetics. 10: 1-8.

Bui Huu Doan \& Nguyen Van Luu (2006). A survey on distribution, conformation, growth and productivity of Ho chicken. Vietnam Journal of Agricultural Sciences. 4: 95-99.

Do Thi Hue, Nguyen Van Duy, Nguyen Thi Xuan, Do Duc Luc, Le Thi Tham, Dang Vu Binh \& Vu Dinh Ton (2017). Semen quality and some factors affecting the semen quality of Dong Tao chicken. Vietnam Journal of Agricultural Sciences. 5: 598-604 (in Vietnamese).

Dao Thi Hiep (2013). Production efficiency and consumption of some local chicken breeds: the case study of Ho and Dong Tao chickens: Hanoi University of Agricultural.

Dottavio A. M., Canet Z. E., Alvarez M., Creixell B., Di Masso R. J. \& Font M. T. (2001). Productive traits in hybrid hens with Fayoumi maternal genotype. Archivos Latinoamericanos de Producción Animal. 9 (2). Retrieved from https://dialnet.unirioja.es/servlet/articulo?codigo $=506$ 9646 on July 2, 2019.

Duong Thi Anh Dao \& Vu Thi Cuc (2011). Studing on some growing and reproductive characteristics of H'mong chickens reared under scavenging and semidustrial conditions in Thuan Chau - Son La. Journal of Animal Husbandry Sciences and Technics. 12:14-20.

GSO (2018). Statistical handbook of Hanoi; Statistical Publishing House.

FAO (2008). Poultry systems in Vietnam Prepared by Duc N. V. \& Long T. GCP/RAS/228/GER working paper No. 4. Rome. Retrieved from http://www.fao.org/3/al693e/al693e00.pdf on May 25, 2019.

MARD (2016). Atlas of livestock breeds in Vietnam, Ministry of Agriculture and Rural Development (in Vietnamese).

Moula N., Antoine-Moussiaux N., Farnir F \& Leroy P. (2009). Comparison of egg composition and conservation ability in two Belgian local breeds and one commercial strain. International Journal of Poultry Science. 8: 768-774.

Ngo Thi Kim Cuc (2010). Vietnamese local chicken breeds: Genetic diversity and prioritizing breeds for conservation. PhD Thesis. Georg-August Universität.

Nguyen Hoang Thinh, Pham Kim Dang, Vu Thi Thuy Hang, Hoang Anh Tuan \& Bui Huu Doan (2017). Phenotypical Characteristics and Productive Performance of Multi-Toes Chicken Raised in The National Park of Xuan Son, Tan Son District, Phu Tho Province. Journal of Sciences and Development. 14: 920 (in Vietnamese).

Nguyen Thi Phuong, Hoang Ngoc Mai, Nguyen Van Duy \& Vu Dinh Ton (2017). Reproductivity and egg quality of H'mong chicken. Animal production in Southeast 
Asia: Current status and Future. July 21-22, 2017. Vietnam National University of Agricultural, Hanoi, Vietnam: 27-32 (in Vietnamese).

Nguyen Van Duy, Do Duc Luc, Nguyen Thi Xuan, Nassim Moula, Vu Dinh Ton \& Frédéric Farnir (2017). Dong Tao chicken: characteristics of an indigenous breed with big legs in Vietnam. The $4^{\text {th }}$ FARAH-Day, 13 October 2017. Faculty of Veterinary Medicine, University of Liège - Belgium: 58.

Nguyen Van Duy, Nassim Moula, Pham Kim Dang, Dao Thi Hiep, Bui Huu Doan, Vu Dinh Ton \& Frédéric Farnir (2015). Ho Chicken in Bac Ninh Province (Vietnam): From an Indigenous Chicken to Local Poultry Breed. International Journal of Poultry Science. 14(9): 521-528.

Özbey O \& Esen F. (2007). The effects of different breeding systems on egg productivity and egg quality characteristics of rock partridges. Poultry Science. 86: 782-785.

Pham M. H., Berthouly-Salazar C, Tran X. H, Chang W. H, Crooijmans R. P, Lin D. Y, Hoang V. T, Lee Y. P, Tixier-Boichard M \& Chen C. F. (2013). Genetic diversity of Vietnamese domestic chicken populations as decision-making support for conservation strategies. Animal Genetics. 44: 509-521.

Lan Phuong T. N, Dong Xuan K. D. T \& Szalay I. (2015). Traditions and local use of native Vietnamese chicken breeds in sustainable rural farming. World's Poultry Science Journal. 71: 385-396.

Tůmová E., Englmaierova M., Ledvinka Z. \& Charvatova V. (2011). Interaction between housing system and genotype in relation to internal and external egg quality parameters. Czech Journal of Animal Science. 56: 490-498. 